\title{
FONTES ORAIS DE INFORMAÇÃO COMO RECURSO DE ENSINO E APRENDIZAGEM
}

\section{FUENTES ORALES DE INFORMACIÓN COMO UN RECURSO DE ENSEÑANZA Y APRENDIZAJE}

\author{
Maria José Sandra de Araujo Terciotti* \\ Sueli Bortolin**
}

\begin{abstract}
Introdução: As fontes orais de informação têm como base a voz humana. Propõe-se neste trabalho que elas sejam utilizadas como recurso de ensino e aprendizagem na escola, em especial na biblioteca escolar.

Objetivo: Identificar as fontes orais para o ensino e aprendizagem na biblioteca escolar.

Metodologia: A investigação tem natureza qualitativa e utiliza como técnica a pesquisa bibliográfica.

Resultados: A biblioteca escolar como instituição social precisa valorizar e incluir as fontes orais em seu acervo para enriquecer o ensino e a aprendizagem na escola.

Conclusões: As fontes orais utilizadas de forma presencial ou à distância são fundamentais para levar os aprendentes, em especial da atual geração, a se apropriar de conteúdos apresentados em sala de aula, bem como de outros que possam suprir suas necessidades de informação.
\end{abstract}

Palavras-chave: Fontes orais. Oralidade. Fontes audiovisuais. Recursos de aprendizagem. Biblioteca escolar.

\section{INTRODUÇÃO}

As tecnologias vêm ocupando todos os espaços possíveis de convivência humana, não sendo diferente nas unidades informacionais do ambiente educacional. Esse cenário faz com que o bibliotecário repense seu papel e ações, procurando adaptar-se, adquirindo para a biblioteca novas 
formas de acesso e suportes da informação e adequando-se à inovação com criatividade. O profissional atuante na biblioteca escolar (BE) deve possibilitar o uso efetivo das tecnologias de informação e comunicação (TIC), a fim de atender satisfatoriamente às expectativas da comunidade usuária. $\mathrm{Na}$ atualidade há vários suportes de fontes de informação, no entanto, vamos nos ater às fontes orais que podem ser entendidas como recursos que utilizam a voz humana para transmissão da informação.

A escolha do tema teve origem na necessidade de evidenciar a biblioteca como elemento essencial para o ensino e a aprendizagem e como incentivadora do gosto pela leitura, especialmente entre o público infantojuvenil. Além disso, visou apontar meios que façam o aluno utilizar efetivamente a biblioteca e seus recursos; sendo, então, o objetivo geral desta pesquisa identificar as fontes orais para o ensino e aprendizagem na $B E$. $A$ metodologia para alcançar este objetivo tem natureza qualitativa e utiliza como técnica a pesquisa bibliográfica.

O indivíduo pode começar a desenvolver sua autonomia de estudo na $\mathrm{BE}, \mathrm{o}$ que naturalmente fará com que os alunos futuramente frequentem outras unidades informacionais que contribuirão para a sua contínua formação; ficando evidente a necessidade do profissional que estiver à frente de uma unidade de informação, principalmente no ambiente de ensino e aprendizagem, apresentar e disponibilizar o uso de fontes orais como um recurso para estudo e pesquisa, bem como de leitura e divertimento.

\section{BIBLIOTECA ESCOLAR NO ENSINO E APRENDIZAGEM}

Considerada como centro de aprendizagem, a BE caracteriza-se como um referencial informacional, comunicacional e de interatividade. Somando-se a isso há o fomento à leitura, ao aprendizado, a atitude científica; ao mesmo tempo estimulando o estudante a redescobrir e ampliar seus conhecimentos e preparando-o para a academia científica (MORENO, 2014).

Conforme consta no Manifesto IFLA/UNESCO para Biblioteca Escolar a missão desta consiste em promover: "Serviços de apoio à aprendizagem e 
livros aos membros da comunidade escolar, oferecendo-lhes a possibilidade de se tornarem pensadores críticos e efetivos usuários da informação [...]" (INTERNATIONAL FEDERATION OF LIBRARY ASSOCIATIONS, 1999, p.1).

Buscando conceituações a respeito da BE em documentos brasileiros, encontra-se no artigo $2^{\circ}$ da Lei № 12.244 de 2010 o seguinte discurso: "[...] considera-se biblioteca escolar a coleção de livros, materiais videográficos e documentos registrados em qualquer suporte destinados à consulta, pesquisa, estudo ou leitura" (BRASIL, 2010). Ao compor o seu acervo é necessário diferentes tipos de materiais informacionais como: livros, periódicos, CDs, DVDs, e-books etc. Isto indica que o documento impresso ou eletrônico oferece apoio aos professores e alunos, pois estes materiais se tornam fontes importantíssimas de informação.

Para que o aluno se sinta fascinado pela biblioteca, esta deverá ter ambiente acolhedor, organizado que disponibilize variados suportes informacionais, como atrativos para leituras e pesquisas (ALMEIDA, 2016).

Acredita-se que, além disso, a biblioteca deva ser um ambiente de autoeducação em que o aprendente possa ampliar seus conhecimentos constantemente. Uma BE atuante é um centro de recursos e aprendizagem, essencial para a integração da comunidade educacional, pois enriquece o que é transmitido pelo professor, podendo este conteúdo ser mais bem apreendido.

Reforçando a importância da diversidade e dos suportes de recursos informacionais disponibilizados na BE, Santos Neto $(2016$, p.5) aponta que "[...] a escolha dos itens que comporão o acervo da biblioteca escolar refletirá no ensino e na aprendizagem, os dispositivos informacionais que ela dispõe interferem no aprendizado e na apropriação pelo aluno".

Vale destacar que a BE só consegue contribuir com a aprendizagem dos alunos quando há: parceria entre professor e bibliotecário, recursos informacionais disponíveis e iniciativas que venham ao encontro das necessidades educacional e cultural dos alunos. Nesse enfoque, também a estrutura física, mobiliário, e principalmente os recursos informacionais e os produtos ofertados pela biblioteca constituem elementos imprescindíveis na formação do indivíduo. Outro elemento é o trabalho conjunto entre os 
profissionais da educação tende a oportunizar ao aprendente a aquisição de conhecimento e autonomia.

Este fato marca a necessidade de que os alunos aprendam a usar os recursos que a biblioteca dispõe, utilizando outras fontes de informação e pesquisa, como por exemplo, os canais de vídeos que segundo Santos Neto (2016, p.2), são “[...] fontes de informação riquíssimas para o ensino e aprendizagem na ambiência escolar e [...] deveriam ser mais utilizados tanto por quem ensina quanto por quem aprende." Esses recursos podem ser facilmente acessados pela internet e amplia o conhecimento nas disciplinas tornando o aprendizado mais interessante e divertido.

\subsection{Caracterização do Aprendente}

Para compreender o usuário da $B E$, acredita-se que seja necessário conhecer a construção do conceito de infância. Ariés (1981), em sua obra: $A$ história Social da Criança e da Família apresenta um panorama sobre a criança, e menciona que a arte medieval ignorava a existência da infância. As crianças geralmente não eram retratadas, e quando eram caracterizavam-se com os trajes similares a dos adultos e da classe social a que pertenciam, sendo consideradas como adultos em miniatura. Isso porque, de acordo com Ariés (1981, p.156), "[...] o sentimento da infância não existia. [...] O sentimento da infância não significa o mesmo que afeição pelas crianças: corresponde à consciência da particularidade infantil [...] que distingue essencialmente a criança do adulto [...]".

Visto por esta perspectiva fica evidente que o conceito de infância nem sempre esteve presente na sociedade, como explica Ariés (1981, p.65) sobre a descoberta da infância: "[...] começou sem dúvida no século XIII [...]. Mas os sinais de seu desenvolvimento [são] particularmente numerosos e significativos a partir do fim do século XVI e durante o século XVII." Para entender o lugar social que a criança ocupa é necessário analisar seu conceito ao longo dos tempos até a contemporaneidade, pois o comportamento, a estrutura familiar e os fatos da vida social sofrem influências diferentes em épocas distintas na história da humanidade. A respeito disso Ahamad (2009, p.1) afirma que: "A 
infância precisa ser entendida como categoria social de efetiva importância para a sociedade [...]." No decorrer dos séculos, como mostra a história, surgiram diferentes concepções de infância.

De acordo com o desenvolvimento da sociedade, a criança começou a ser valorizada, ganhando a preocupação não apenas em relação às suas necessidades básicas, mas à sua formação como indivíduo, considerando-se, por exemplo, sentimentos, vontades, expectativas. Quando a sociedade passou a ter consciência do universo infantil, leis e direitos foram estabelecidos em favor da criança e ela foi reconhecida com personalidade distinta do adulto.

Assim, por não se fazer distinção entre criança e adulto e o que poderia ser ou não apropriado para ela, a criança recebia maior atenção nos primeiros anos de vida, enquanto ainda dependia dos cuidados da mãe, depois de desmamada vivia no mundo e na realidade da vida adulta, adquirindo conhecimentos desse convívio com os mais velhos (ARIÉS, 1981).

Pode-se considerar que a importância dada à criança surgiu no século XIX quando a infância passou a ser reconhecida e as crianças começaram a frequentar a escola, entendendo que nesta fase da vida o indivíduo está em formação e necessita de cuidados, sendo resguardado de situações ou fatos que podem influenciar ou prejudicar seu desenvolvimento.

O Estatuto da Criança e do Adolescente (ECA) em seu Art. $2^{\circ}$ afirma que a criança é: "[...] a pessoa até doze anos de idade incompletos, e adolescente aquela entre doze e dezoito anos de idade" (BRASIL, 1990). Nem sempre a família está atenta às fases de amadurecimento de seus filhos, visto que a correria do dia a dia ou outros motivos como o comodismo acabam permitindo, mesmo inconscientemente que a vida de adulto e suas particularidades interrompam a infância. Normalmente os pais não param para ouvir e ver o que as crianças estão fazendo, sendo negligentes em acompanhar seu desenvolvimento, deixando de preservar as etapas do período infantil e interferindo na expressividade e na linguagem.

A criança hoje está inserida em um mundo diferente daquele do início do século $X X$. Em meio à tecnologia surgem novos artigos infantis, que por meio das mídias e publicidade transformam a criança num consumidor sempre à 
espera de novidades. Isto consequentemente afeta as relações sociais da criança, e em muitos casos prejudica sua formação, levando-a a sempre querer mais; podendo criar assim uma sensação de não saciedade e uma busca desenfreada por consumir itens muitas vezes desnecessários e descartáveis.

Como visto, até pouco tempo a criança era considerada como um "adulto em miniatura", mas na contemporaneidade os avanços tecnológicos, a concepção da criança e sua linguagem passaram a ter outro reconhecimento. Deste modo ela é compreendida como sujeito histórico e social. Com tanta tecnologia presente nas atividades do dia a dia e a midiatização da informação, observa-se a geração mais jovem escrevendo e trocando mensagens nas telas de celulares, compartilhando vídeos com rapidez, acessando constantemente e enviando conteúdos de todas as categorias.

Estas formas de transmissão de informação, com visualizações frequentes e simultâneas de vídeos e recursos orais, principalmente nos dispositivos móveis, demonstram os novos modos de aprender e se divertir das crianças e jovens.

Por outro lado as bibliotecas, em sua maioria, ainda insistem em oferecer apenas documentos impressos. Isso provoca falta de interesse em utilizar a biblioteca, pois os aprendentes estão diariamente conectados em tecnologias, vídeos, sons, mídias e, possivelmente, têm pouco contato com livros; isso desmotiva os alunos, pois desejam agilidade, gostam de ouvir, visualizar vídeos e ter acesso rápido na internet.

Nesse contexto, com as possibilidades que a internet oferece, há o contato e interesse em adentrar neste ambiente virtual. Nele as "[...] crianças utilizam o aparelho celular desde muito cedo, aprenderam a manusear as teclas ou telas com habilidade e principalmente utilizando apenas os dedos polegares." (VIGNOLI; BORTOLIN, 2014, p.50). Assim interagem em casa, na escola ou onde conseguem conexão na web.

Diante dessa realidade, a biblioteca como centro de recursos de aprendizagem e os profissionais que estão à sua frente precisam adaptar-se e criar condições quanto à utilização da internet na formação educacional e cultural dos aprendentes. O uso dela permitiu uma intensificação dos fluxos 
informacionais e maior interatividade comunicacional, onde acontece a busca, a troca, a disseminação, o acesso e a rápida propagação das informações, o que possibilita transformações sociais e organizacionais, bem como a necessidade de inovação no ensino e na aprendizagem.

O Manifesto da IFLA sobre a Internet defende que "A liberdade de acesso à informação, independentemente de suporte e fronteiras, é uma responsabilidade da biblioteca e dos profissionais da informação" (INTERNATIONAL FEDERATION OF LIBRARY ASSOCIATIONS, 2002, p.3), cabendo ao bibliotecário por meio de ferramentas e conhecimentos técnicos ser o elo entre os recursos oferecidos pela biblioteca e a comunidade escolar.

\section{FONTES ORAIS}

Vivemos numa sociedade que está se reinventando a todo o momento e realiza descobertas que incluem novas formas de comunicação. Com a utilização dos meios audiovisuais há a recuperação da oralidade, conservando a presença da voz. Com os discursos apresentados até aqui, é possível afirmar que as fontes orais podem ser entendidas como recursos que utilizam a voz para transmitir algo que é repassado do emissor ao receptor sem estar impressa.

Bortolin e Almeida Júnior (2015, p.59) conceituam fontes orais como: "[...] aquelas que têm como base a voz [...]", são formas de expressão oral fundamentais nas relações humanas e imprescindível no desenvolvimento de pesquisas nos espaços de informação, cultura e leitura.

Para Santos Neto (2016) fontes orais de informação são aquelas que disponibilizam informação utilizando a oralidade, sejam elas mediatizadas ou não. As fontes orais surgem das tradições orais em que o conhecimento era disseminado de uma geração a outra, e isto faz com que os acontecimentos sejam perpetuados por meio da escuta, observação, imitação, repetição e/ou da memória humana.

Apesar do prazer em se contar ou ouvir história, há uma distinção entre os textos orais e os escritos como apontado por Bortolin (2010, p.15), "[...] 
sendo o segundo mais valorizado do que o primeiro e, consequentemente, a oralidade, pelo menos na Biblioteconomia, envolve um número reduzido de pesquisadores".

Os textos orais possuem a característica de transpor o tempo e espaços, como os arquivos e a memória histórica. Neste contexto, temos também as mídias que contribuem para a reconstituição da história, com a preservação e conservação de documentos e as obras monumentais que são fontes de conhecimento. Pode-se citar como exemplo as palestras em eventos e as postagens no YouTube.

\subsection{Fontes Audiovisuais}

Há dois tipos de fontes de informação: as formais e as informais, estas "[...] são mais rápidas e exigem menos esforço; em contrapartida, as fontes formais demandam uma maior atenção, tempo e desgaste intelectual. Porém, uma não anula a outra, ambas são importantes na construção do conhecimento." (BUENO, 2006, p.4).

Assim, entende-se que as fontes de informação são recursos utilizados para atender a uma necessidade informacional, podendo ser apresentadas em vários suportes que contêm ou indicam a informação desejada, como as fontes audiovisuais. Audiovisual de acordo com o Dicionário de Comunicação é uma palavra composta por áudio, que deriva do latim audire (ouvir; som) e visual, do latim videre (ver). Consistem em sistemas, meios, veículos que propagam uma mensagem por meio de uma linguagem; mensagem transmitida da combinação de som, imagem e eventualmente escrita, como: os filmes sonoros de cinema e televisão, projeções de slides com áudio, vídeo-arte, videoclipe e outros (AUDIOVISUAL, 2009).

Toda comunicação audiovisual acontece através dos sentidos: auditivos - emissões de rádio, gravações, linguagem oral; ou visuais - linguagem gráfica, fotografias, ilustrações, cartazes de filmes, capas de DVD, outdoors, pinturas e tatuagens, até mesmo corporais.

Outra definição de audiovisual, encontrada no Dicionário da Ciência da Comunicação, é: "[...] Processo de comunicação de massas que não exclui 
uma componente lúdica. Dele se servem a informação, a publicidade e a propaganda. A televisão é o meio audiovisual mais divulgado." (AUDIOVISUAL, 2000, p.28).

Conforme as definições nos parágrafos anteriores entende-se que as fontes audiovisuais são recursos que detêm conteúdos representados pela combinação de som e imagem. Assim necessitam de um suporte eletrônico ou mecânico para que a mensagem seja transmitida e apreendida através dos sentidos auditivo e visual. Portanto, estas características as qualificam como ferramentas para o ensino e a aprendizagem.

De acordo com Farias Júnior (2014) o termo audiovisual começou a ser utilizado nos Estados Unidos da América por volta da primeira metade do século $\mathrm{XX}$, quando os progressos tecnológicos permitiram a transição do cinema mudo para o cinema falado. Com o passar do tempo os recursos audiovisuais adquiriram popularidade em virtude do cinema sonoro e da televisão. "O fato é que cada vez mais, cercamo-nos de imagens e sons, produzidos por intermédio de equipamentos específicos como televisão, vídeo, celulares, computadores e seus recursos midiáticos." (FARIAS JÚNIOR, 2014, p.1). Para este autor é necessária a busca por novas formas de interpretar e repensar a construção do conhecimento no ambiente escolar, lembrando que o aluno é o elemento principal nesse contexto.

Nascimento (2001) destaca que a evolução tecnológica marca uma mudança de comportamento social e comunicacional, diante dos diversos meios de comunicação e da forma pela qual a mensagem ou conhecimento é transmitido; como exemplo cita a internet.

Para Tomaél et al. (2001, p.3) "De fato, a Internet abriu um leque amplo na tipologia de fontes de informação pois, além das convencionais, vão surgindo novas fontes até agora não caracterizadas e reconhecidas totalmente na literatura".

Juntamente com o avanço e inovações tecnológicas, a comunicação propiciou a difusão de mensagens e imagens veiculadas em suportes audiovisuais com sentidos visual e sonoro que permitem uma forma atrativa na assimilação e compreensão de conteúdos na escola. 
Por meio do acesso à informação, utilizando-se da leitura em variados suportes informacionais, o educando deve tornar-se apto ao exercício da cidadania. No processo de ensino e aprendizagem está inserida a BE como elemento essencial para as dinâmicas pedagógicas, interferindo no aprendizado e na formação do indivíduo (ALMEIDA, 2016). Ela é um ambiente de aprendizagem em completa interação com a sala de aula, podendo fazer uso dos recursos audiovisuais, ofertando suportes como: CDs, DVDs, filmes, imagens digitais, serviços e atividades elaboradas e desenvolvidas a partir desses recursos, como será reforçado a seguir.

\subsubsection{YouTube como ferramenta de ensino e aprendizagem}

YouTube foi criado em 2005 com o objetivo de possibilitar que as pessoas compartilhassem seus vídeos de viagens. No entanto, surpreendentemente fugindo de seu objetivo inicial tornou-se um sítio com dimensão mais abrangente, contendo vídeos que são utilizados como fonte de informação em diversas áreas do conhecimento humano (CAETANO; FALKEMBACH, 2007). É o sítio de compartilhamento de vídeos mais difundido entre os usuários da internet. Atualmente trata-se de uma forma de escrever, interagir, comunicar, compartilhar, transmitir imagens, vídeos e músicas (CARVALHO et al., 2013).

A respeito do YouTube, Pellegrini et al. (2016, p.3) o descreve como: "[...] um serviço online de vídeos que permite a seus usuários carregá-los, compartilhá-los, produzi-los e publicá-los em formato digital através de websites, aparelhos móveis, blogs e e-mails".

Moran (1995, p.28) destaca a importância do uso de vídeos como apoio ao ensino, eliminando a barreira da sala de aula versus livro. Para ele: "O vídeo é sensorial, visual, linguagem falada, linguagem musical e escrita. [...]. Nos atingem por todos os sentidos e de todas as maneiras. O vídeo nos seduz, informa, entretém, projeta em outras realidades (no imaginário), em outros tempos e espaços".

Dallacosta (2004), reforçando o pensamento de Moran, afirma que o vídeo é um instrumento complementar ao trabalho do professor, pois possibilita 
o ensino com um linguajar direto, claro, objetivo, sobre um determinado conteúdo. Pode-se utilizar o vídeo no ensino de qualquer área do conhecimento humano, bem como na matemática, na física e no ensino da leitura, colaborando com o aprendizado de forma dinâmica.

Na concepção de Fialho $(2009$, p.2) "[...] o YouTube se apresenta como uma peça fundamental na transição de escolas analógicas para digitais [...]". Tal afirmação pode ser comprovada em Falkembach (2005, p.3) quando alerta que "Uma aplicação hipermídia educacional, ou seja, um courseware pode ser formado por uma lição, pelo conteúdo de uma aula, um curso, um programa de treinamento, uma unidade curricular ou uma atividade didática qualquer".

Para Kamers (2013) é inerente ao homem sempre "experimentar" o novo, e as mídias presentes em nosso cotidiano estão modificando a maneira como aprendemos e nos comunicamos, em especial, as novas gerações que fazem uso dessas tecnologias com muita desenvoltura e rapidez.

Veen e Vrakking (2009) afirmam que o ensino tradicional reduz em significativa escala a quantidade de fontes de informação e de atividades, controlando o acesso à informação aos alunos e impedindo de certa maneira o desenvolvimento de suas habilidades e percepções, tornando o ensino tradicional negativo ao desenvolvimento da criança.

Os "[...] recursos oferecidos pelas tecnologias digitais possibilitam criar materiais educativos que podem estimular o aprendiz tornando-o um cúmplice do processo de aprendizagem e engajando-o no processo do seu desenvolvimento" (FALKEMBACH, 2005, p.1). Neste ambiente, o professor se torna um elo entre o conhecimento e estas tecnologias com o uso de materiais educativos digitais, desde pequenas atividades realizadas via computador ou ainda livros eletrônicos, jogos, simulações, histórias em quadrinhos, desafios propostos aos alunos, oportunizando ao aprendiz o desenvolvimento do raciocínio (FALKEMBACH, 2005).

O vídeo contribui para o desenvolvimento e aprendizado do indivíduo e estando ele na internet, possibilita o acesso de conteúdos informacionais de significativa importância no aprendizado educacional. Isto mudou o comportamento dos aprendizes que: "além de consumirem, fazem questão de 
se representarem [...] há uma necessidade de troca. Ou seja, um conteúdo produzido numa cidadezinha do interior, por exemplo, pode hoje ser acessado por internautas dos grandes centros mundiais." (PELLEGRINI et al., 2016, p.3).

Este discurso representa o conceito atual do YouTube, uma vez que diariamente são postados inúmeros vídeos com a intenção de compartilhar informações. A qualquer pessoa é permitido criar uma conta e publicar seus vídeos, realizando comentários promovendo a interação socioeducativa. Além de ampliar seus conhecimentos, pode opinar criticamente.

\subsubsection{Audiolivro como material de apoio à leitura}

$\mathrm{Na}$ literatura em língua portuguesa encontra-se a definição de audiolivro como um livro em áudio, também chamado de livro falado ou audiobook. Para Menezes e Franklin (2008, p.59) ele é "[...] um recurso informacional gerado pelas novas tecnologias, que pode ser utilizado não apenas pelos deficientes visuais, como também por pessoas sem deficiência, cooperando com a formação e o resgate de leitores". Estes autores destacam que o audiolivro, por meio dos seus "ledores" voluntários ou profissionais que interpretam textos literários, científicos ou didáticos, provocam diferentes sentimentos em suas apresentações aos ouvintes.

Vallejo (2015) destaca que a entonação da voz deve variar de acordo com seu gênero (didático, literário, roteiro de teatro, entre outros), e ser direcionada à faixa etária do ouvinte. Em sua dissertação de mestrado sobre $O$ processo de produção de audiolivros no Instituto Benjamin Constant identificou algumas características como: "[...] a gravação do audiolivro deve ser livre de ruídos ou outras interferências, o locutor deverá possuir uma voz clara e bem timbrada e com um ritmo nem lento e nem excessivamente rápida" (VALLEJO, 2015, p.74). A respeito do desempenho dos alunos ele afirma ainda que: "[...] ao lerem o audiolivro apresentaram crescimento médio ao reconhecimento de palavras novas, melhoria da compreensão global do texto, do ritmo e velocidade de leitura e [...] maior interesse por essa habilidade." (VALLEJO, 2015, p.71). 
Em relação ao desempenho dos professores, Vallejo (2015) afirma ser possível conciliar o uso dos audiolivros como suporte e incentivo para a leitura concomitantemente com os textos impressos. O audiolivro disponível no formato mp3 proporciona a sua leitura em dispositivos móveis, tais como smartphones, tablets, mp3 player, entre outros.

Ainda há, segundo Souza, Celva e Helvadjian (2010, p.32) a praticidade que o audiolivro apresenta, podendo ser "lido/ouvido" ao mesmo tempo em que se executam outras tarefas diárias, "[...] como exercícios físicos, uma viagem ou uma volta pela cidade". Segundo estes autores o audiolivro "[...] é um recurso pedagógico que motiva e desperta interesse, favorável, portanto a sua aceitabilidade [...] além do letramento literário, resgata e valoriza a leitura e a oralidade." (SOUZA; CELVA; HELVADJIAN, 2010, p.34).

Neste contexto Oliveira et al. (2016, p.257) afirmam que "[...] as histórias e contos infantis constituem fontes de sabedoria e possuem importante papel na formação da identidade dos indivíduos".

Os leitores devem vivenciar um texto corporalmente, por meio de vários sentidos. Ao ouvir histórias de um livro impresso ou de um audiolivro o aluno aguça sua curiosidade, possibilitando-lhe construir novas ideias e consequentemente resolver questões de seu cotidiano.

Diante do exposto fica evidente que a utilização do YouTube e do audiolivro contribui para a aprendizagem e permite aos aprendentes ter contato com o mundo literário desde as séries iniciais, pois estes recursos podem ser utilizados por meio de um televisor, computador, dispositivos móveis, entre outros. Assim, acredita-se que os recursos audiovisuais como fontes de informação podem ser ferramentas que permitem uma melhor apreensão dos conteúdos ensinados em sala de aula.

\section{PROCEDIMENTOS METODOLÓGICOS}

A presente pesquisa tem um enfoque qualitativo, utilizando o método bibliográfico que: "Compreende a busca e análise sistemática da informação, contida em um acervo documental bibliográfico, cujos parâmetros são 
cuidadosamente especificados e seguem procedimentos adequados aos objetivos e norteadores da mesma." (WITTER, 1990, p.24).

A busca de documentos para subsidiar o referencial teórico da pesquisa foi realizada no Google, Google Acadêmico, base de dados Scielo, portal de revistas científicas da área de Biblioteconomia e na Base de Dados Referencial de Artigos de Periódicos em Ciência da Informação (BRAPCl). Para isso utilizou-se as seguintes palavras-chave: fontes orais, oralidade, recurso de aprendizagem, fontes audiovisuais e biblioteca escolar.

A revisão bibliográfica ou levantamento bibliográfico "[...] é de fundamental importância para a formulação do problema de pesquisa. Todavia, por si só, ele é insuficiente. Requer-se a reflexão crítica a cerca dos assuntos estudados [...]." (GIL, 2006, p.63). Estas reflexões foram possíveis graças às fontes impressas aqui utilizadas, mas também às fontes orais, isto é, os docentes e os discentes do curso de especialização em Gestão de Biblioteca Escolar ofertado no Departamento de Ciência da Informação da Universidade Estadual de Londrina.

\section{RESULTADOS E CONSIDERAÇÕES FINAIS}

Ao desenvolver essa pesquisa abordou-se os aspectos teóricos sobre a oralidade e as fontes orais, que são próprias à humanidade, como as atividades desempenhadas pelo homem, suas vivências e experiências que são transmitidas por meio da voz. Percebe-se na atualidade que com a utilização dos meios audiovisuais recupera-se a oralidade e conserva-se a presença da voz, sendo que os textos orais possuem a característica de transpor o tempo e espaços, e com as mídias comunicacionais que podem ser utilizadas em ambientes educacionais, isso se amplia.

Diante dos atuais recursos informacionais e os meios digitais, como as mídias audiovisuais e a internet, surgem novos modos de leitura e de escrita e, consequentemente, o indivíduo também é influenciado na forma de agir e pensar. 
$\mathrm{Na}$ escola, bibliotecários e educadores precisam repensar o currículo e os métodos de ensino, bem como a aquisição de recursos informacionais no gênero audiovisual como uma fonte valiosa de pesquisa, informação, comunicação e conhecimento. Além de dar maior visibilidade a $B E$ mostrando seu potencial e garantindo o reconhecimento da comunidade em que ela está inserida.

A utilização de dispositivos móveis contribui para a autonomia e inclusão digital e para a construção do conhecimento, principalmente na formação integral do educando. Conceber a biblioteca como centro de aprendizagem ressalta o seu valor nas práticas cotidianas de ensino e aprendizagem. Para tanto, ela necessita ser dinâmica e desenvolver atividades de importância para a comunidade escolar; deve ampliar e possibilitar o uso efetivo da informação audiovisual, pois em meio ao acesso digital a adoção dos recursos audiovisuais pela BE dinamiza seu potencial e ampliar o acesso a conhecimentos nunca antes imagináveis.

A BE como instituição social precisa valorizar e incluir as fontes orais em seu acervo para enriquecer o ensino e a aprendizagem na escola. Defende-se ainda que as crianças e jovens necessitam aprender além dos conteúdos básicos, buscando novos conhecimentos e saberes que estão sendo produzidos ao seu redor ou em outros territórios.

\section{REFERÊNCIAS}

AHAMAD, L. A. S. Um breve histórico da infância e da instituição de educação infantil. Revista Partes, São Paulo, jun. 2009. Disponível em:

<httpllwww.partes.com.br/educacao/historicodainfancia.asp>. Acesso em: 12 out. 2015.

ALMEIDA, M. de A. F. M. A importância da biblioteca escolar no ensino e aprendizagem da leitura e escrita. Disponível em:

$<$ http://coordenacaoescolagestores.mec.gov.br/uft/file.php/1/moddata/data/100 3/1221/2591/A_Importancia_da_Biblioteca_Escolar_no_Ensino_e_Aprendizage m_da_Leitura_e_Escrita.pdf >. Acesso em: 10 jan. 2016. 
ARIÉS, P. História social da criança e da família. 2. ed. Rio de Janeiro: LTC, 1981.

AUDIOVISUAL. In: MARCONDES FILHO, C. (Org.). Dicionário da comunicação. São Paulo: Paulus, 2009. p. 31.

AUDIOVISUAL. In: LEÃO, I. V. P. de. Dicionário de ciências da comunicação: dicionários temáticos. Porto: Ed. Porto, 2000. p. 28.

BORTOLIN, S. Mediação oral da literatura: a voz dos bibliotecários lendo ou narrando. 2010. 232 f. Tese (Doutorado em Ciência da Informação) Universidade Estadual Paulista, Faculdade de Filosofia e Ciências, Marília, 2010.

BORTOLIN, S.; ALMEIDA JÚNIOR, O. F. de. Fontes orais, Paul Otlet e os bibliotecários. In: BORTOLIN, S.; SANTOS NETO, J. A. dos, SILVA, R. J. da (Org.). Mediação oral da informação e da leitura. Londrina: Abecin, 2015. p.59-88.

BRASIL. Presidência da República. Casa Civil. Subchefia para Assuntos Jurídicos. Lei n. 12.244, de 24 de maio de 2010. Dispõe sobre a universalização das bibliotecas nas instituições de ensino do país. Disponível em: <http://www.planalto.gov.br/ccivil_03/_ato2007-2010/2010/lei/l12244.htm>. Acesso em: 10 fev. 2016.

BRASIL. Presidência da República. Casa Civil. Subchefia para Assuntos Jurídicos. Lei № 8.069, de 13 de julho de 1990. Dispõe sobre o Estatuto da Criança e do Adolescente e dá outras providências. Disponível em: <http://www.planalto.gov.br/ccivil_03/leis/L8069.htm>. Acesso em: 10 fev. 2016.

BUENO, S. B. Acesso e uso da informação no ambiente educacional: as fontes de informação. Revista ACB: Biblioteconomia em Santa Catarina, Florianópolis, v. 11, n. 1, p. 53-62, jan./jul. 2006. Disponível em: $<$ http://revista.acbsc.org.br/racb/article/view/464/583>. Acesso em: 10 out. 2015.

CAETANO, S. V. N.; FALKEMBACH, G. A. M. You Tube: uma opção para uso do vídeo na EAD. In: CICLO DE PALESTRAS SOBRE NOVAS TECNOLOGIAS NA EDUCAÇÃO, 9., 2007, Porto Alegre. Anais... Porto Alegre, 2007. Disponível em: <http://www.cinted.ufrgs.br/ciclo9/artigos/3aSaulo.pdf>. Acesso em: 15 jun. 2016.

CARVALHO, J. et al. Análise de vídeos do youtube sobre aleitamento materno: importância e benefício. Revista de Enfermagem UFPE, Recife, v. 7, n. 3, mar. p.1016-1022, 2013. Disponível em: <http://www.revista.ufpe.br/ revistaenfermagem/index.php/revista/article/viewFile/3530/pdf_2307>. Acesso em: 9 jul. 2016. 
DALLACOSTA, A. Possibilidades educacionais do uso de vídeos anotados no youtube. 2004. Disponível em: <http://www.ensino.eb.br/portaledu/ conteudo/artigo9513.pdf>. Acesso em: 6 jul. 2016.

FALKEMBACH, G. A. M. Concepção e desenvolvimento de material educativo digital. Revista Renote - Novas Tecnologias na Educação, Porto Alegre, v.3 n.1, p. 1-15, maio 2005. Disponível em: <http://www.seer.ufrgs.br/article/download/13742/7970>. Acesso em: 10 fev. 2016.

FARIAS JÚNIOR, J. P. de. O uso de fontes audiovisuais e novas mídias no ensino de história antiga na educação básica. História e-História, Campinas, fev. 2014. Disponível em: <http://historiaehistoria.com.br/materia.cfm? $\mathrm{tb}=$ artigos\&id=257>. Acesso em: 18 jul. 2015.

FIALHO, V. R. Do vídeo cassete ao Youtube. a (r)evolução do uso do vídeo na sala de aula de línguas estrangeiras. In: ENCONTRO NACIONAL SOBRE HIPERTEXTO, 3., 2009, Belo Horizonte. Anais...Belo Horizonte: CEFET, 2009. p.1-12. Disponível em: <https://www.ufpe.br/nehte/hipertexto2009/anais/b-f/dovideocassete-ao-youtube.pdf>. Acesso em: 17 jun. 2016.

GIL, A. C. Como elaborar projetos de pesquisa. 4. ed. São Paulo: Atlas, 2006.

INTERNATIONAL FEDERATION OF LIBRARY ASSOCIATIONS [IFLA]. IFLA Manifesto sobre a Internet. 2002. Disponível em:

$<$ http://www.ifla.org/files/assets/faife/publications/policy-documents/internetmanifesto-pt.pdf>. Acesso em: 9 jul. 2016.

Manifesto IFLA/UNESCO para biblioteca escolar. 1999. Disponível em: <http://archive.ifla.org/VII/s11/pubs/portuguese-brazil.pdf>. Acesso em: 18 fev. 2016.

KAMERS, N. J. O youtube como ferramenta pedagógica no ensino de física. 2013. 177 f. Dissertação (Mestrado em Educação) - Universidade do Estado de Santa Catarina - UDESC, Florianópolis, 2013.

MENEZES, N. C.; FRANKLIN, S. Audiolivro: uma importante contribuição tecnológica para os deficientes visuais. Ponto de Acesso, Salvador, v.2, n.3, p. 58-72, dez. 2008. Disponível em: <http://www.portalseer.ufba.br/index.php/ revistaici/article/view/3213/2337>. Acesso em: 13 jul. 2016.

MORAN, J. M. O vídeo em sala de aula. Revista Comunicação \& Educação, São Paulo, n. 2, p.27-35, jan./abr. 1995. 
MORENO, E. A. Diagnóstico das bibliotecas escolares do município de Jaraguá do Sul segundo a lei 12.244/2010. Revista ACB: Biblioteconomia em Santa Catarina, Florianópolis, v. 19, n. 1, p. 23-32, jan./jun. 2014. Disponível em: <http://revista.acbsc.org.br/racb/article/view/946/pdf_84>. Acesso em: 2 fev. 2016.

NASCIMENTO, M. I. M. Marshall McLuhan. Revista Educação, Ponta Grossa, n. 46, n. 10, 2001. Disponível em: <http://www.histedbr.fe.unicamp.br/ navegando/glossario/verb_b_marshall_mcluhan.htm>. Acesso em: 20 jan. 2016.

OLIVEIRA, M. de et al. Audiobooks como ferrementa pedagógica na educação inclusiva de deficientes visuais. Revista Eletrônica em Gestão, Educação e Tecnologia Ambiental, Santa Maria, v. 20, n. 1, p. 254-256, jan./abr. 2016. Disponível em: <http://periodicos.ufsm.br/reget/article/download/15571/pdf>. Acesso em: 8 jul. 2016.

PELLEGRINI, D. P. et al. Youtube: uma nova fonte de discursos. Disponível em: <http://www.bocc.ubi.pt/pag/bocc-pelegrini-cibercultura.pdf>. Acesso em: 10 jul. 2016.

SANTOS NETO, J. A. dos. Biblioteca escolar e as fontes orais de informação. In: SILVA, R. J. da; BORTOLIN, S. Fazeres cotidianos da biblioteca escolar. Londrina: Abecin, 2016 (no prelo).

SOUZA, M. S. D. de; CELVA, R. A.; HELVADJIAN, V. Audiolivro: um suporte para a educação literária. Leitura, Teoria e Prática, Campinas, v.28, n.55, p.28-36, 2010. Disponível em:

<https://tp.emnuvens.com.br/ltp/article/viewFile/69/66>. Acesso em: 6 jul. 2016.

TOMAÉL, M. I. et al. Avaliação de fontes de informação na internet: critérios de qualidade. Revista Informação \& Sociedade, João Pessoa, v. 11, n. 2, p. 114, 2001 Disponível em:

<http://www.ies.ufpb.br/ojs/index.php/ies/article/viewFile/ 293/216>. Acesso em: 10 jun.2016.

VALLEJO, A. de O. O processo de produção de audiolivros no Instituto Benjamin Constant. 85 f. 2015. Dissertação (Mestrado em Educação) Universidade Estácio de Sá - UNESA, Rio de Janeiro, 2015. Disponível em: <http://www.portalseer.ufba.br/index.php/revistaici/article/view/3213/2337>. Acesso em: 9 jul. 2016.

VEEN, W.; VRAKKING, B. Homo zappiens: educando na era digital. Porto Alegre: Artmed, 2009. 
VIGNOLI, R. G.; BORTOLIN, S. A biblioteca escolar e as mediações com a geração polegar. Biblioteca Escolar em Revista, Ribeirão Preto, v. 2, n. 2, p. 45-59, maio/ago. 2014. Disponível em: <http://revistas.ffclrp.usp.br/BEREV/ article/viewFile/303/pdf>. Acesso em: 30 abr. 2016.

WITTER, Geraldine Porto. Pesquisa bibliográfica, pesquisa documental e busca da informação. Estudos de Psicologia, Campinas, v.7, n.1, p.5-30, jan./jul.1990.

\title{
Title
}

Oral sources of information as a resource for teaching and learning

\begin{abstract}
Introduction: Oral sources of information are based on human voice. We propose in this paper their use as a teaching and learning resource at school, especially in the school library.

Objective: To identify oral sources for teaching and learning in the school library.

Methodology: The investigation has a qualitative nature and uses bibliographic research as technique.

Results: The school library as social institution needs to value and include oral sources in its collection to enrich teaching and learning at school.

Conclusions: Oral sources, either in classroom or at a distance, are fundamental to lead the learners, especially of the present generation, to take ownership of the contents presented in the classroom, as well as of others that might supply their information needs.
\end{abstract}

Keywords: Oral sources. Orality. Audio-visual sources. Learning resources. School library.

\section{Titulo}

Fuentes orales de información como un recurso de enseñanza y aprendizaje

\section{Resumen}

Introducción: Las fuentes orales de información se basan en la voz humana. Se propone en este trabajo que ellas sean utilizadas como recurso de enseñanza y aprendizaje en la escuela, en especial en la biblioteca escolar.

Objetivo: Identificar las fuentes orales para la enseñanza y el aprendizaje en la biblioteca escolar.

Metodología: La investigación tiene naturaleza cualitativa y utiliza como técnica la investigación bibliográfica.

Resultados: La biblioteca escolar como institución social necesita valorizar e incluir las fuentes orales en su acervo para enriquecer la enseñanza y el aprendizaje en la escuela. 
Conclusiones: Las fuentes orales utilizadas de forma presencial oa distancia son fundamentales para llevar a los alumnos, en especial de la actual generación, a apropiarse de contenidos presentados en el aula, así como de otros que puedan suplir sus necesidades de información.

Palabras clave: Fuentes orales. Oralidad. Fuentes audiovisuales. Recursos de aprendizaje. Biblioteca escolar.

Recebido: 10.03 .2017

Aceito: 10.11.2017 